\section{Military Technical College Kobry El-Kobbah, Cairo, Egypt}

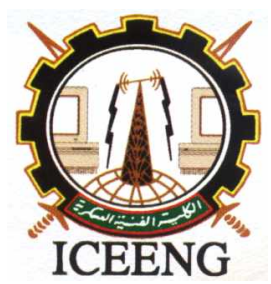

\title{
Load modeling effect on voltage stability of large scale power systems
}

\author{
$6^{\text {th }}$ International Conference \\ on Electrical Engineering \\ ICEENG 2008
}

By
M. M. Abu-Elnaga*
A. Y. Abdelaziz*
A. M. Abdeen*
M. A. Badr*

\section{Abstract:}

Steady state voltage stability analysis is effectively used to determine a stability margin that shows how close the current operating point of a power system to the voltage collapse point. The energy function technique represents a powerful method to assess voltage stability of multi-machine power systems. The sparse network formulation of this method retains the original structure of the system network and avoids network reduction. This permits the system loads to be modeled as they exist in practical life. Neglecting these models may lead to misleading results; e.g. the system appears to be stable while it is actually unstable. This paper investigates this serious problem and shows the significant effect of load modeling on power system voltage stability. A closed form expression of the energy function is obtained. The proposed technique is applied to Ontario-Hydro real power system (Canada).

\section{Keywords:}

Voltage stability, energy function, and load models.

* Department of Electrical Power and Machines, Faculty of Engineering, Ain Shams University, Cairo, Egypt

\section{Introduction:}

Voltage stability is a subset of the overall power system stability. A power system is said to be voltage stable if (at a given operating state) is subjected to a given disturbance, the voltage near the loads approaches a post-disturbance equilibrium point. 
On the other hand, a power system is said to have a voltage collapse, if the equilibrium voltage after the disturbance is found to be below acceptable limits. In recent years, voltage instability has been responsible for several major network collapses [1]. As a consequence, voltage control and stability problems are now receiving special attention in most systems. Several factors contribute to this voltage collapse [2]; stressed power systems, inadequate reactive power resources due to excitation system limits, and also, load characteristics at low voltage are crucial and differ from those at normal values. Therefore, maintaining an adequate margin from voltage instability limits is a major concern because many utilities are loading their bulk transmission networks to their maximum possible capability without increasing transmission capability. Accordingly, an accurate, easily computable indicator of the proximity of the system to voltage collapse is needed to take the most effective preventive control actions [3].

Several approaches have been developed for power system voltage stability assessment. Static voltage stability indices have been obtained based on singular value decomposition of the power flow Jacobian matrix together with the singular vectors [4]. A voltage proximity index, based on the voltage phasor values, has been proposed in $[5,6]$. A performance index that provides a direct relationship between its value and the amount of load demand that the system can withstand before collapse has been proposed in [7]. Usefulness and limitations of bifurcation theory in network studies and operation, particularly in voltage stability related issues have been presented in [8-10].

The proximity of a power system to the voltage collapse point has been evaluated by Eigenvalue-Eigenvector analysis of load flow Jacobian matrix of the system $[11,12]$. The relationship between multiple load flow solutions and voltage instability has been discussed in [13]. The values of the total active and reactive power losses of a power system have been used as a good indicator for power system voltage stability [14]. Artificial Neural Networks (ANN) has been, also, used in voltage stability assessment problem [15-17].

The energy function technique represents a powerful method to determine both the transient stability [18,19] and voltage stability of multi-machine power systems [20,21]. The sparse network formulation of this method retains the original structure of the system network and avoids network reduction [22]. This permits the system loads to be modeled as they exist in practical life. Neglecting these models may lead to misleading results; e.g. the system appears to be stable while it is actually unstable. The serious effect of load modeling on transient stability of multi-machine power systems has been discussed in [23] and [24].

This paper investigates this serious problem and shows the significant effect of load 
modeling on power system voltage stability. A closed form expression of the energy function including load modeling effect is obtained. The proposed technique is applied to Ontario-Hydro (55-bus) real power system (Canada).

\section{Current Energy Function Technique:}

In transient stability analysis, the energy function is known as Transient Energy Function (TEF). The calculation of the TEF depends mainly on determining the postfault Stable Equilibrium Point (SEP) and the Unstable Equilibrium Point (UEP) of minimum energy [19]. In voltage stability assessment of multi-machine power systems, the energy function technique is a vector integration of both active and reactive power mismatch equations with integration limits of the high and low voltage power flow solutions (HVS and LVS). The high and low voltage power flow solutions may be, physically, explained by considering the two-bus system with lossless transmission line shown in Fig. (1) [25].

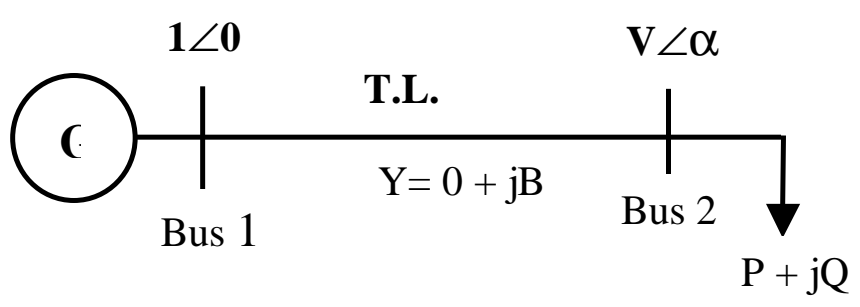

Figure (1): Two-bus system.

Fig. (2) shows a plot of $\alpha-V$ (voltage angle and magnitude) relations for different values of active and reactive load powers (P and $\mathrm{Q}$ ) with a transmission line susceptance $B=10.0$ p.u. The constant "P" and constant "Q" curves have typically two intersections, each corresponding to a power flow solution. One of them is referred as HVS (e.g. points $\mathrm{A}$ and $\mathrm{C}$ ) and the other is referred as LVS (e.g. points D and B). In a case where the two curves are tangent to each other (HVS and LVS are the same) we get the collapse point. The energy function that represents the height of the potential barrier between the HVS and LVS is defined as [25]: 


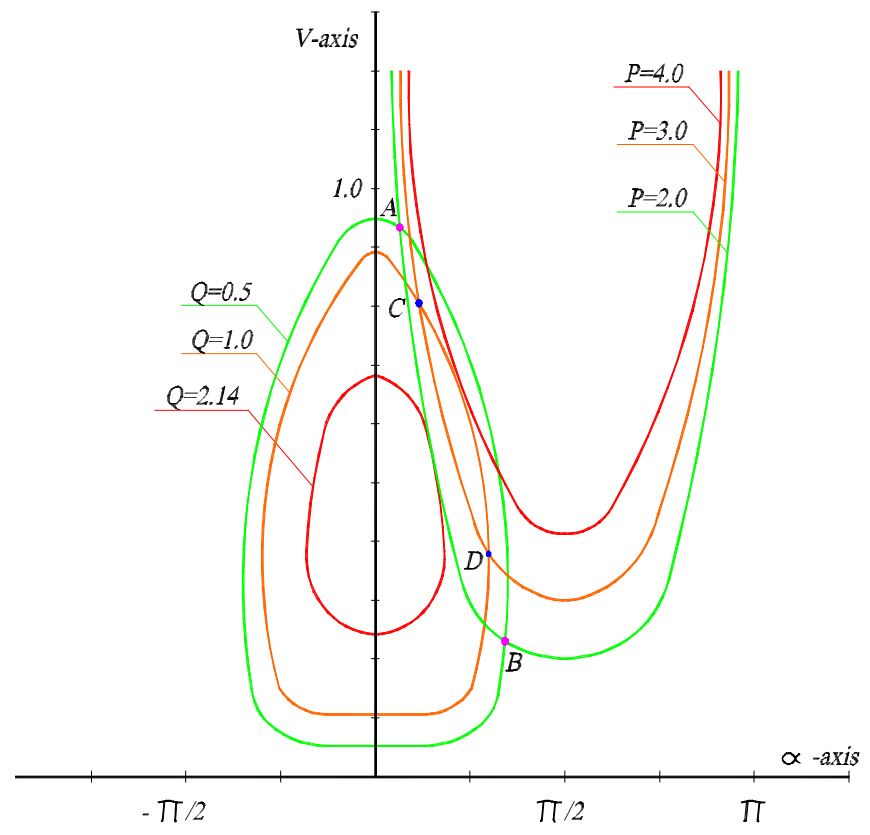

Figure (2): HVS and LVS points for the Two-bus system.

$$
v(\omega, V)=\int_{0}^{\omega} M_{g} \omega \cdot d \omega+\int_{\alpha^{o}, V^{o}}^{\alpha, V} f(\alpha, V) \cdot d \alpha+\int_{\alpha^{o}, V^{o}}^{\alpha, V} g(\alpha, V) \cdot d V
$$

Accordingly, a generalized energy function, which is devoted for constant power load model, has been formulated for voltage stability assessment of multi-machine power systems [22]. It has the following final form:

$$
\begin{aligned}
v(\omega, \alpha, V)= & \sum_{\substack{j=1 \\
j \neq i}}^{n} Y_{i j} V_{i} V_{j} \sin \left(\beta_{i j}-\alpha_{j}+\alpha_{i}\right)-\sum_{\substack{j=1 \\
j \neq i}}^{n} Y_{i j} V_{i}^{o} V_{j} \sin \left(\beta_{i j}-\alpha_{j}+\alpha_{i}^{o}\right)-P_{i}\left(\alpha_{i}-\alpha_{i}^{o}\right) \\
& +Q_{i} \ln \frac{V_{i}}{V_{i}^{o}}+\frac{1}{2} B_{i i}\left(V_{i}^{2}-V_{i}^{o^{2}}\right)+\int_{\substack{\left(\alpha_{\mathrm{i}}^{o}, \mathrm{v}_{\mathrm{i}}^{o}\right) \\
\left(\alpha_{i}, \mathrm{v}_{\mathrm{i}}\right)}}^{n} \sum_{\substack{j=1 \\
j \neq i}}^{n} Y_{i j} V_{j} \sin \left(\beta_{i j}-\alpha_{j}+\alpha_{i}\right) . d V
\end{aligned}
$$

The Left-Hand-Side (LHS) of the load flow equations which can be expressed (for nbus system) in polar form as:

$$
\begin{aligned}
& P_{i}=\sum_{j=1}^{n} Y_{i j} V_{i} V_{j} \cos \left(\beta_{i j}+\delta_{j}-\delta_{i}\right) \\
& Q_{i}=-\sum_{j=1}^{n} Y_{i j} V_{i} V_{j} \sin \left(\beta_{i j}+\delta_{j}-\delta_{i}\right)
\end{aligned}
$$


Equation (2) gives the Energy Margin (EM) - the voltage stability index - of a multi-machine power system considering all system parameters. As explained in [22], Equations (3) and (4) give the required HVS and LVS at a load power. To get the voltage collapse, the load power is gradually increasing at a specified bus "i" by a certain step while keeping the loads at all other buses fixed. At each step, the load flow calculations are performed to obtain both the HVS and LVS. We keep increasing the loads till the point of voltage collapse is reached and any further increase in load will lead to system failure.

\section{Proposed Energy Function with Load Modeling:}

In the current application of energy function technique [22], the system loads, the LHS of Equations (3) and (4), are assumed constant. The proposed composite load model consists of constant power, constant current and constant impedance loads. The constant power load (CPL) absorbs more current from the system at low voltage conditions and vice versa. The constant impedance load (CIL) varies as the square of voltage magnitude and, accordingly, absorbs less power, compared to constant power load, at lower voltage. Constant current load (CCL) is directly proportional to the voltage magnitude and it represents an intermediate condition between the previous two types. Therefore, the proposed composite load model, that is more realistic as compared with that currently adopted, can be represented as:

$$
\begin{aligned}
& \mathrm{P}_{\mathrm{L}}=\mathrm{P}+\mathrm{P}_{\mathrm{I}}+\mathrm{P}_{\mathrm{Z}}=\mathrm{P}+\mathrm{CPI} * \mathrm{~V}+\mathrm{CPZ} * \mathrm{~V}^{2} \\
& \mathrm{Q}_{\mathrm{L}}=\mathrm{Q}+\mathrm{Q}_{\mathrm{I}}+\mathrm{Q}_{\mathrm{Z}}=\mathrm{Q}+\mathrm{CQI} * \mathrm{~V}+\mathrm{CQZ} * \mathrm{~V}^{2}
\end{aligned}
$$

where: $\mathbf{P}$ and $\mathbf{Q}$ are the active and reactive constant power load component.

$\mathbf{P}_{\mathbf{I}}$ and $\mathbf{Q}_{\mathbf{I}}$ are the active and reactive constant current load component.

$\mathbf{P}_{\mathbf{Z}}$ and $\mathbf{Q}_{\mathbf{Z}}$ are the active and reactive constant impedance load component.

CPI and CQI are the constants of proportionality for the constant current load.

CPZ and CQZ are the constants of proportionality for the constant impedance load.

The constant impedance load component at each bus can be added to the diagonal elements of the bus admittance matrix, therefore, Equations (5-a) and (5-b) can be written as:

$$
P_{i}+C P I_{i} * V_{i}=Y_{i i} V_{i}^{2} \cos \left(\beta_{i i}\right)+\sum_{\substack{j=1 \\ j \neq i}}^{n} Y_{i j} V_{i} V_{j} \cos \left(\beta_{i j}-\alpha_{j}+\alpha_{i}\right)
$$




$$
Q_{i}+C Q I_{i} * V_{i}=-Y_{i i} V_{i}^{2} \sin \left(\beta_{i i}\right)-\sum_{\substack{j=1 \\ j \neq i}}^{n} Y_{i j} V_{i} V_{j} \sin \left(\beta_{i j}-\alpha_{j}+\alpha_{i}\right)
$$

where $\mathbf{Y}_{\mathbf{i i}}$ includes the shunt admittance connected at bus $\mathbf{i}$ and the constant impedance load at that bus. Then, writing the constraint functions as:

$$
\begin{gathered}
f(\alpha, V)=Y_{i i} V_{i}^{2} \cos \left(\beta_{i i}\right)+\sum_{\substack{j=1 \\
j \neq i}}^{n} Y_{i j} V_{i} V_{j} \cos \left(\beta_{i j}-\alpha_{j}+\alpha_{i}\right)-P_{i}-C P I_{i} * V_{i} \\
g(\alpha, V)=V_{i}^{-1}\left[Q_{i}+C Q I_{i} * V_{i}+Y_{i i} V_{i}^{2} \sin \left(\beta_{i i}\right)+\sum_{\substack{j=1 \\
j \neq i}}^{n} Y_{i j} V_{i} V_{j} \sin \left(\beta_{i j}-\alpha_{j}+\alpha_{i}\right)\right]
\end{gathered}
$$

Recalling Equation (1), the energy function expression has three terms. The $1^{\text {st }}$ term, denoted by I1, will lead to:

$$
\mathbf{I 1}=0.5 \quad \mathbf{M}_{\mathrm{g}} w^{2}
$$

The second term of Equation (1), denoted by $\mathbf{I} 2$, is given by:

$$
\begin{aligned}
\mathbf{I 2}= & \int_{\left(\alpha_{\mathrm{io}}, \mathrm{V}_{\mathrm{io}}\right)}^{\left(\alpha_{i}, \mathrm{~V}_{\mathrm{i}}\right)} f(\alpha, V) \cdot d \alpha \\
\mathbf{I 2}= & \int_{\left(\alpha_{\mathrm{io}}, \mathrm{V}_{\mathrm{io}}\right)}^{\left(\alpha_{i}, \mathrm{~V}_{\mathrm{i}}\right)} Y_{i i} \cdot V_{i}^{2} \cdot \cos \beta_{i i} \cdot d \alpha+\int_{\left(\alpha_{\mathrm{io}}, \mathrm{V}_{\mathrm{io}}\right)}^{\left(\alpha_{i}, \mathrm{~V}_{\mathrm{i}}\right)} \sum_{\substack{j=1 \\
j \neq i}}^{n} Y_{i j} \cdot V_{i} \cdot V_{j} \cos \left(\beta_{i j}-\alpha_{j}+\alpha_{i}\right) \cdot d \alpha \\
& -\int_{\left(\alpha_{\mathrm{io}}, \mathrm{V}_{\mathrm{io}}\right)}^{\left(\alpha_{i}, \mathrm{~V}_{\mathrm{i}}\right)} P_{i} \cdot d \alpha-\int_{\left(\alpha_{\mathrm{io}}, \mathrm{V}_{\mathrm{io}}\right)}^{\left(\alpha_{i}, \mathrm{~V}_{\mathrm{i}}\right)} C P I_{i} * V_{i} \cdot d \alpha
\end{aligned}
$$

Performing the required mathematical manipulation, we get: 


$$
\begin{aligned}
\text { I2 }= & G_{i i}\left(V_{i}^{3}-V_{i o}{ }^{3}\right) / 3 m+\sum_{\substack{j=1 \\
j \neq i}}^{n} Y_{i j} \cdot V_{j} \cdot V_{i} \cdot \sin \left(\beta_{i j}-\alpha_{j}+\alpha_{i}\right) \\
& -\sum_{\substack{j=1 \\
j \neq i}}^{n} Y_{i j} \cdot V_{j} \cdot V_{i o} \cdot \sin \left(\beta_{i j}-\alpha_{j}+\alpha_{i o}\right)-\sum_{\substack{j=1 \\
j \neq i}}^{n} Y_{i j} \cdot V_{j} \int_{\left(\alpha_{i}^{0}, V_{i}^{0}\right)}^{\left(\alpha_{i}, V_{\mathrm{i}}\right)} \sin \left(\beta_{i j}-\alpha_{j}+\alpha_{i}\right) \cdot d V \\
& -P_{i}\left(\alpha_{i}-\alpha_{i o}\right)-C P I_{i}\left(V_{i}^{2}-V_{i o}{ }^{2}\right) / 2 m
\end{aligned}
$$

where $: m=\left(V_{o}-V\right) /\left(\alpha_{o}-\alpha\right)$

The third term of Equation (1), denoted by $\mathbf{I 3}$, is given by:

$$
\begin{aligned}
& \int_{\left(\alpha_{\mathrm{i}}^{\mathrm{o}}, \mathrm{V}_{\mathrm{i}}^{\mathrm{o}}\right)}^{\left(\alpha_{i}, \mathrm{~V}_{\mathrm{i}}\right)} Q_{i} / V_{i} \cdot d V+\int_{\left(\alpha_{\mathrm{i}}^{0}, \mathrm{~V}_{\mathrm{i}}^{\mathrm{o}}\right)}^{\left(\alpha_{i}, \mathrm{~V}_{\mathrm{i}}\right)} C Q I_{i} \cdot d V+\int_{\left(\alpha_{\mathrm{i}}^{\mathrm{o}}, \mathrm{V}_{\mathrm{i}}^{\mathrm{o}}\right)}^{\left(\alpha_{i}, \mathrm{~V}_{\mathrm{i}}\right)} Y_{i i} \cdot V_{i} \cdot \sin \left(\beta_{i i}\right) \cdot d V
\end{aligned}
$$

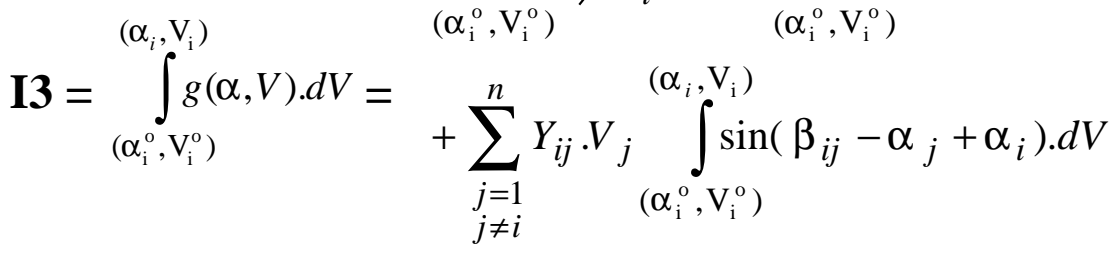

Performing the required mathematical manipulation, we get:

$$
\begin{aligned}
\mathbf{I 3}= & Q_{i} \cdot \ln \left(V_{i} / V_{i o}\right)+C Q I{ }_{i}\left(V_{i}-V_{i o}\right)+\frac{1}{2} B_{i i}\left(V_{i}^{2}-V_{i o}^{2}\right) \\
& +\sum_{\substack{j=1 \\
j \neq i}}^{n} Y_{i j} \cdot V_{j} \int_{\left(\alpha_{\mathrm{i}}^{\circ}, \mathrm{V}_{\mathrm{i}}^{\circ}\right)}^{\left(\alpha_{i}, \mathrm{~V}_{\mathrm{i}}\right)} \sin \left(\beta_{i j}-\alpha_{j}+\alpha_{i}\right) \cdot d V
\end{aligned}
$$

Collecting the previous terms I1, I2 and I3, we get: 


$$
\begin{aligned}
& \frac{1}{2} M_{g} \cdot w^{2}+G_{i i}\left(V_{i}^{3}-V_{i o}{ }^{3}\right) / 3 m+\sum_{\substack{j=1 \\
j \neq i}}^{n} Y_{i j} \cdot V_{j} \cdot V_{i} \cdot \sin \left(\beta_{i j}-\alpha_{j}+\alpha_{i}\right) \\
& -\sum_{\substack{j=1 \\
j \neq i}}^{n} Y_{i j} \cdot V_{j} \cdot V_{i o} \cdot \sin \left(\beta_{i j}-\alpha_{j}+\alpha_{i o}\right)-\sum_{\substack{j=1 \\
j \neq i}}^{n} Y_{i j} \cdot V_{j} \int_{\left(\alpha_{\mathrm{i}}^{\mathrm{o}}, \mathrm{V}_{\mathrm{i}}^{\mathrm{o}}\right)}^{\left(\alpha_{i}, \mathrm{~V}_{\mathrm{i}}\right)} \sin \left(\beta_{i j}-\alpha_{j}+\alpha_{i}\right) \cdot d V
\end{aligned}
$$

$v(w, \alpha, \mathrm{V})=-P_{i}\left(\alpha_{i}-\alpha_{i o}\right)-C P I_{i}\left(V_{i}{ }^{2}-V_{i o}{ }^{2}\right) / 2 m+Q_{i} * \ln \left(V_{i} / V_{i o}\right)+C Q I_{i}\left(V_{i}-V_{i o}\right)$

$$
+\frac{1}{2} B_{i i}\left(V_{i}^{2}-V_{i o}{ }^{2}\right)+\sum_{\substack{j=1 \\ j \neq i}}^{n} Y_{i j} \cdot V_{j} \int_{\left(\alpha_{\mathrm{i}}^{\mathrm{o}}, \mathrm{V}_{\mathrm{i}}^{\mathrm{o}}\right)}^{\left(\alpha_{i}, \mathrm{~V}_{\mathrm{i}}\right)} \sin \left(\beta_{i j}-\alpha_{j}+\alpha_{i}\right) \cdot d V
$$

Taking into considerations the steady state conditions $(w=0)$, the energy function for a multi-machine power system considering all parameters will have the closed form given by Equation (12). The energy function of Equation (12) gives Energy Margin (EM) - the voltage stability index - at any loading conditions.

$$
\begin{aligned}
& G_{i i}\left(V_{i}^{3}-V_{i o}{ }^{3}\right) / 3 m+\sum_{\substack{j=1 \\
j \neq i}}^{n} Y_{i j} \cdot V_{j} \cdot V_{i} \cdot \sin \left(\beta_{i j}-\alpha_{j}+\alpha_{i}\right) \\
\boldsymbol{v}(\boldsymbol{w}, \boldsymbol{\alpha}, \mathbf{V})= & -\sum_{\substack{j=1 \\
j \neq i}}^{n} Y_{i j} \cdot V_{j} \cdot V_{i o} \cdot \sin \left(\beta_{i j}-\alpha_{j}+\alpha_{i o}\right)-P_{i}\left(\alpha_{i}-\alpha_{i o}\right) \\
& -C P I_{i}\left(V_{i}{ }^{2}-V_{i o}{ }^{2}\right) / 2 m+Q_{i} * \ln \left(V_{i} / V_{i o}\right) \\
& +C Q I_{i}\left(V_{i}-V_{i o}\right)+\frac{1}{2} B_{i i}\left(V_{i}{ }^{2}-V_{i o}{ }^{2}\right)
\end{aligned}
$$




\section{APPLICATION RESULTS:}

The voltage collapse point is determined as the point at which the energy margin reaches zero. In the following applications, the load at each bus will be considered as a composite load that described by Equation (5). A gradual increase in active and reactive load power at one load bus only is implemented keeping the power factor constant at that bus.

A computer program is implemented for general application to large-scale power systems with international Power Technology Institute (PTI) data input and dynamic sizing. The flow chart of the computer program is shown in Fig. 3. The load powers are given in per-unit (pu) with a 100 MVA base. The load at each bus will be considered as a composite load of a CPL, CCL and CIL with a variable relative shares.

For example: at a certain bus, if the total power $\left(\mathrm{P}_{\mathrm{L}}\right)$ was equal to 2 p.u. and the load model is: $50 \%$ constant power, $30 \%$ constant current, and $20 \%$ constant impedance, then, the relative shares will be: $\mathrm{CPL}=1 \mathrm{pu}, \mathrm{CCL}=0.6 \mathrm{pu}$, and $\mathrm{CIL}=0.4$ pu., and hence: $\mathrm{CCL}=\mathrm{CPI} * \mathrm{~V}$, and $\mathrm{CIL}=\mathrm{CPZ} * \mathrm{~V}^{2}$.

For the bus at which the load is gradually increased, the values for CPI and CPZ are calculated considering the bus voltage to be nominal. 


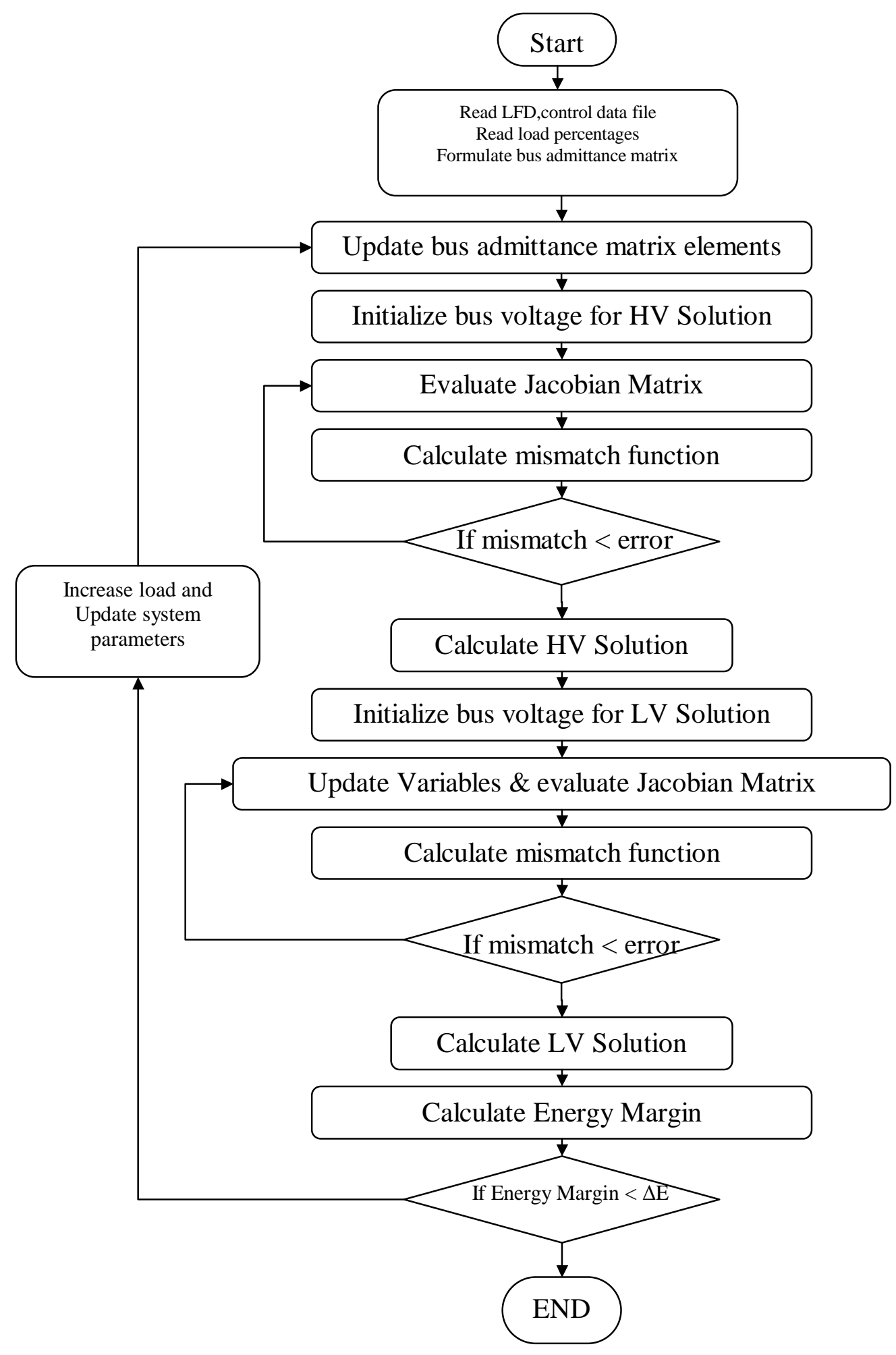

Figure (3): Block diagram of the computer program. 


\section{1-GENERATOR, 55-BUS SYSTEM}

This system is a reduced version of BRUCE system of Ontario Hydro, Canada. This system includes the state of Ontario (Canada) and upper New York area (USA) [26]. This system consists of 11 generator buses and 44 load buses. It should be noted that both resistance and conductance for all transmission lines are considered in this application. The initial total generated power (i.e. before load increasing) for this system is $2641.67 \mathrm{pu}$ for $\mathrm{P}$ and $690.85 \mathrm{pu}$ for Q (with a 100 MVA base).

For the application of the energy function to this system, Three load buses have been elected to represent different load categories: a heavy load bus (bus \#30), a medium load bus (bus \#7) and a light load bus (bus \#149). At each of these selected load buses, different percentages of load have been chosen to cover the whole range of load modeling.

\section{Heavy load bus (bus \#30)}

The active power at bus \#30, which is one of the heavily loaded buses, is 432.69MW. Figure 4 shows the power and voltage behavior if the load modeling is neglected. The Normalized EM (NEM) is the energy margin calculated after each load increase divided by the energy margin for the initial load. Figures 5-7 show the power and voltage behavior for some selected load models. Table 1 shows the main results obtained for that bus for several load models and starting with the classical load model (100\% constant power).
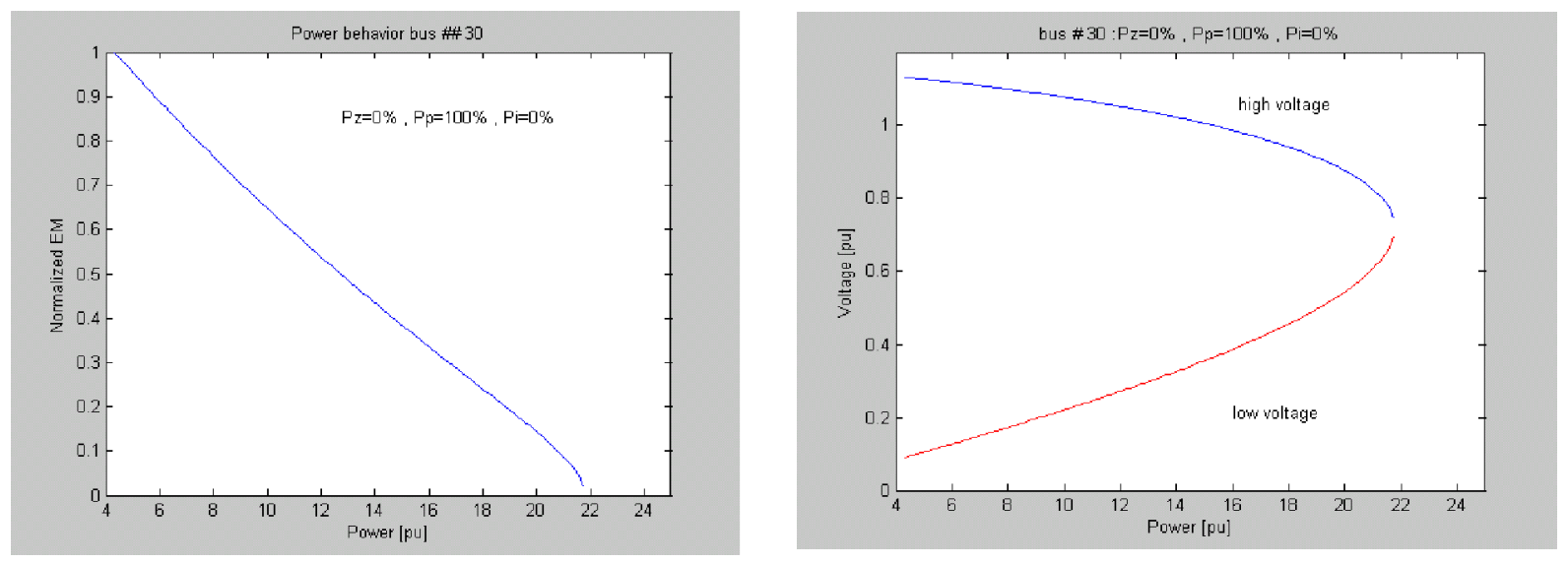

Figure (4): Power and voltage behavior neglecting load modeling

$$
\left(P_{P}=100 \%\right. \text {, ) for bus\#30. }
$$



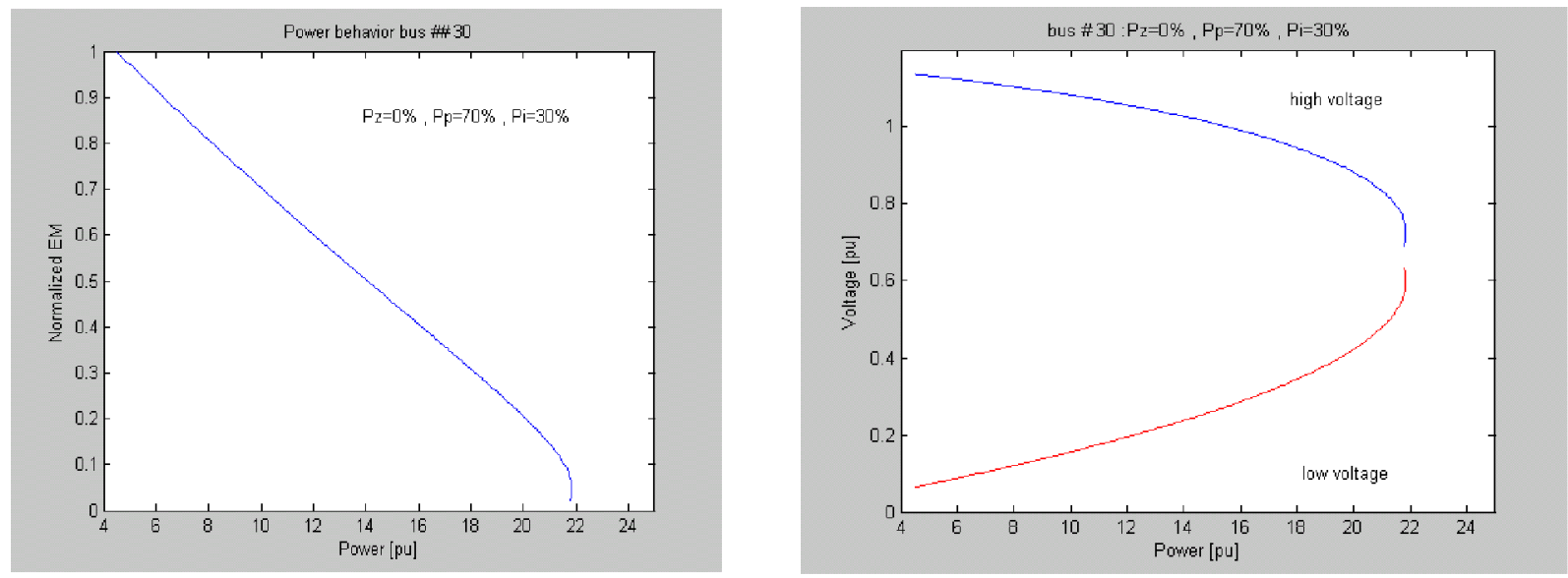

Figure (5): Power and voltage behavior $\left(P_{P}=70 \%, P_{I}=30 \%, P_{Z}=0 \%\right)$ for bus\#30.
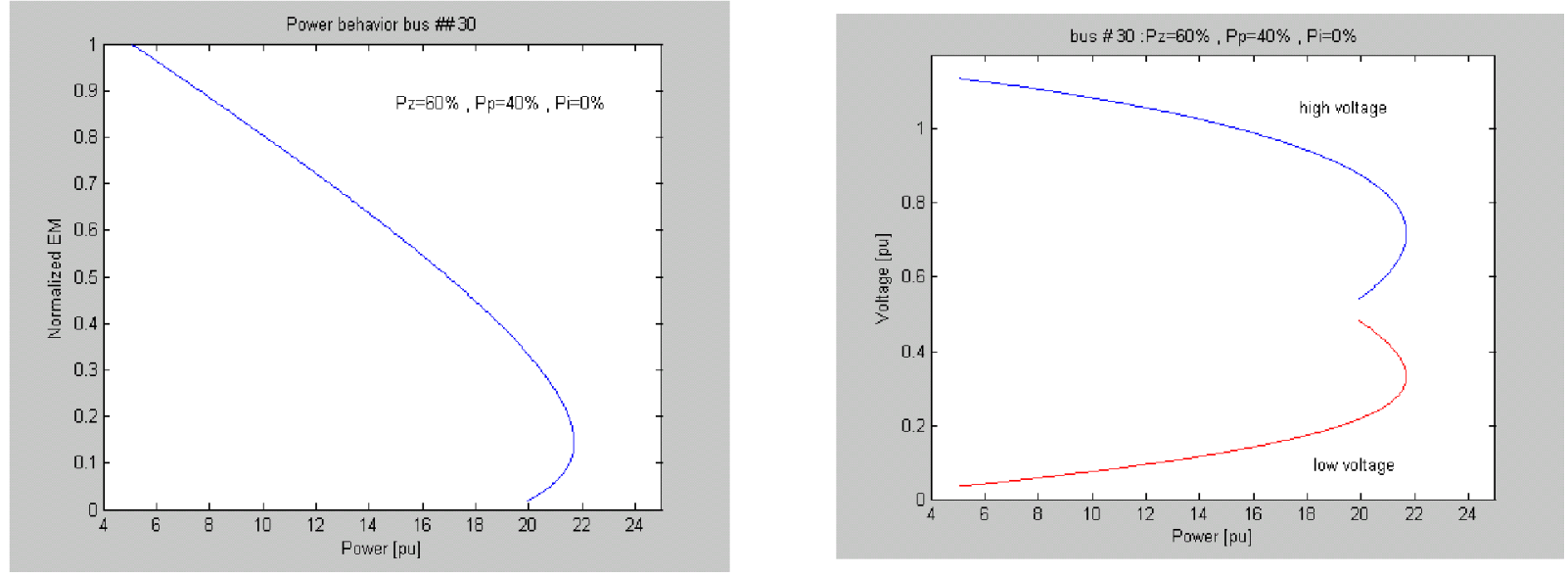

Figure (6): Power and voltage behavior $\left(P_{P}=40 \%, P_{I}=0 \%, P_{Z}=60 \%\right)$ for bus\#30.
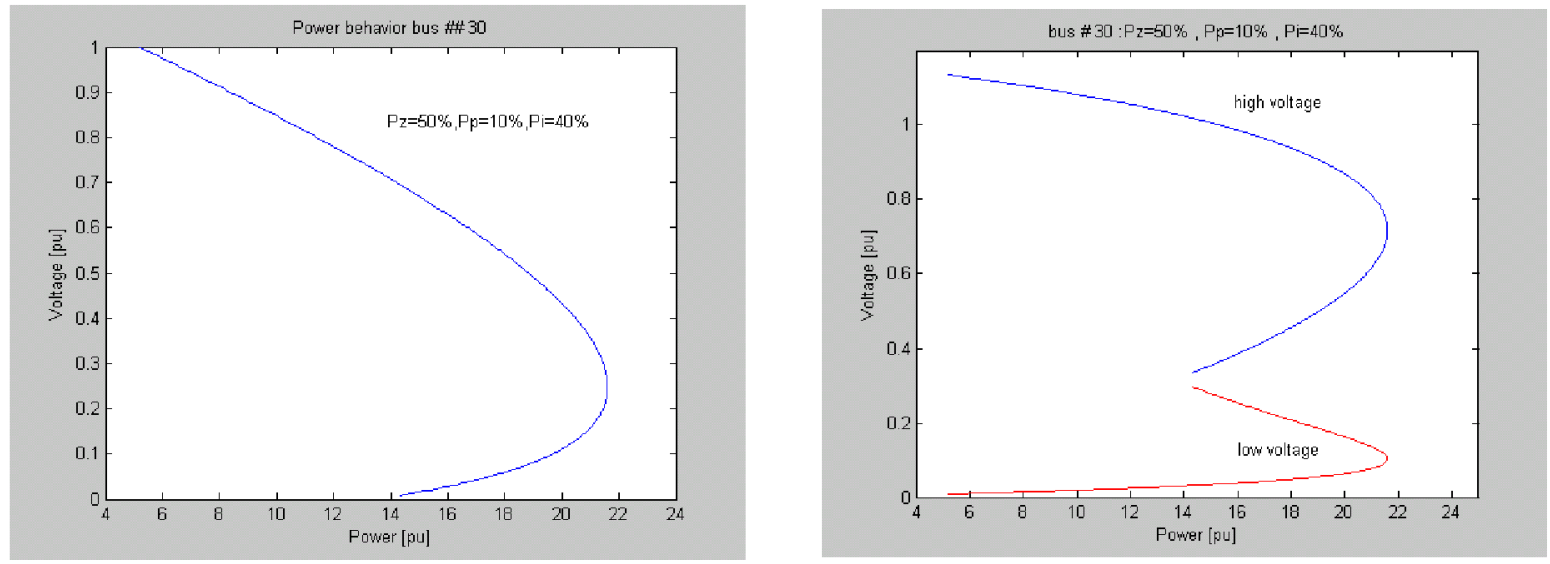

Figure (7): Power and voltage behavior $\left(P_{P}=10 \%, P_{I}=40 \%, P_{Z}=50 \%\right)$ for bus $\# 30$. 
Table (1): Main results for bus\#30 (starting active power $=497.84 \mathrm{MW}$ ).

\begin{tabular}{||c||c||c||c|c|c|c||}
\hline $\begin{array}{c}\text { Constant } \\
\text { power } \\
\text { load[\%] }\end{array}$ & $\begin{array}{c}\text { Constant } \\
\text { current } \\
\text { load[\%] }\end{array}$ & $\begin{array}{c}\text { Constant } \\
\text { impedance } \\
\text { load[\%] }\end{array}$ & $\begin{array}{c}\text { Active } \\
\text { power at } \\
\text { collapse } \\
\text { [pu] }\end{array}$ & $\begin{array}{c}\text { Maximum } \\
\text { power } \\
\text { [pu] }\end{array}$ & $\begin{array}{c}\text { High } \\
\text { Voltage } \\
\text { solution at } \\
\text { collapse[pu] }\end{array}$ & $\begin{array}{c}\text { Low } \\
\text { Voltage } \\
\text { solution at } \\
\text { collapse[pu] }\end{array}$ \\
\hline \hline 100 & 0 & 0 & 21.7269 & 21.7269 & 0.7445 & 0.6980 \\
\hline 70 & 30 & 0 & 21.7754 & 21.8522 & 0.6876 & 0.6366 \\
\hline 70 & 0 & 30 & 21.6556 & 21.8710 & 0.6634 & 0.6102 \\
\hline 40 & 60 & 0 & 20.9928 & 21.8746 & 0.5998 & 0.5405 \\
\hline 40 & 30 & 30 & 20.3367 & 21.8232 & 0.5596 & 0.5205 \\
\hline 40 & 0 & 60 & 19.8936 & 21.7009 & 0.5393 & 0.4857 \\
\hline 10 & 70 & 20 & 15.4983 & 21.7626 & 0.3687 & 0.3229 \\
\hline 10 & 50 & 40 & 14.5016 & 21.6621 & 0.3394 & 0.3106 \\
\hline 10 & 40 & 50 & 14.2881 & 21.6015 & 0.3336 & 0.2981 \\
\hline 10 & 20 & 70 & 13.5971 & 21.4597 & 0.3148 & 0.2834 \\
\hline
\end{tabular}

As shown, the increase in the constant impedance and constant current shares, due to the dependency of these loads on voltage levels, cause a decrease in the total active power especially at low voltage levels before reaching the collapse point. As expected, the incremental increase in load power is followed by a gradual decrease in the high voltage solution and a gradual increase in the low voltage solution. This gradual change continues until reaching a certain power level at which the high voltage solution coincides with the low voltage solution indicating zero energy margin at voltage collapse. As shown, as the constant current and constant impedance load percentages increase, a further decrease in the total power is observed before reaching the collapse point. Also, the voltage magnitude at which voltage collapse occurs is much lower for constant current and constant impedance loads than the voltage magnitudes for constant power loads. This indicates that soft loads (constant current and constant impedance loads) are more stable than stiff loads (constant power loads) as the system is still operating even at very low voltage levels.(i.e.: Stiff loads are the source of voltage instability while soft loads are not ).

\section{Medium load bus (bus \#7)}

The active power at bus \#7 is 228.02MW. Here, we have similar results for those obtained for the heavy load bus (bus \#30). Therefore, only the power and voltage behavior for dominant constant impedance and current loads $\left(P_{P}=10 \%, P_{I}=40 \%\right.$, 
$P_{Z}=50 \%$ ) are shown in Figure 8 . The main results for some selected load models are shown in Table 2.
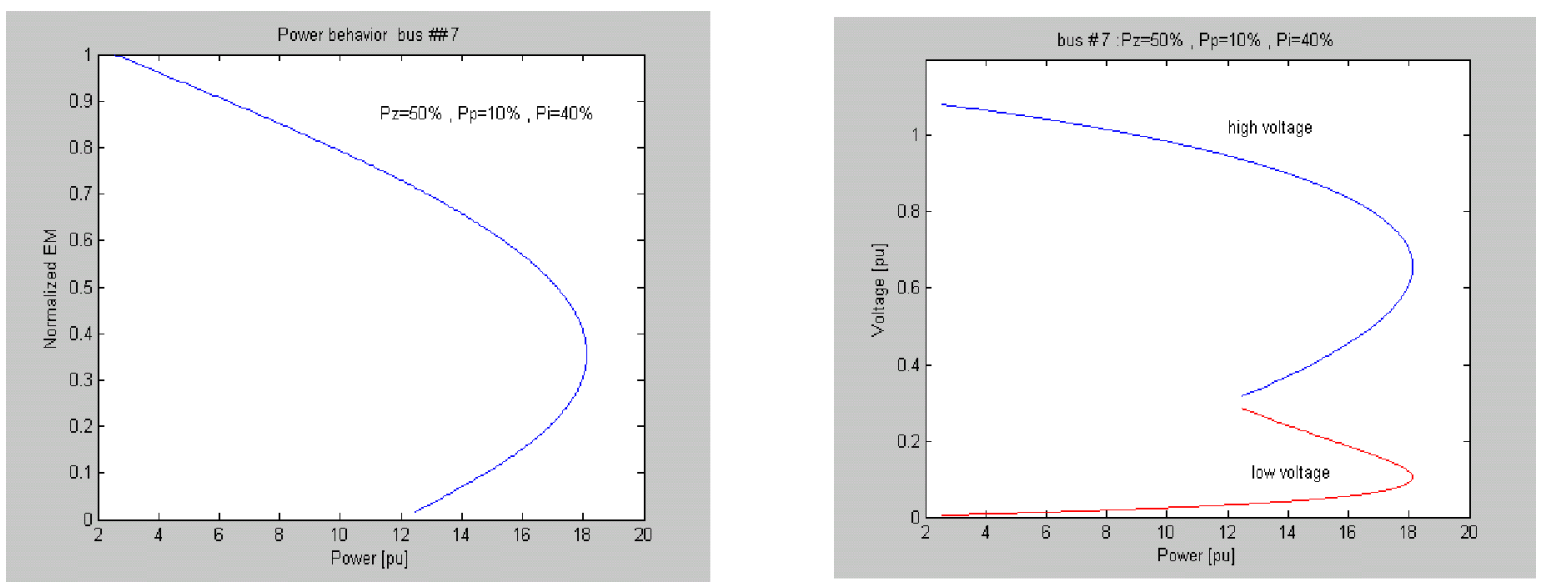

Figure (8): Power and voltage behavior $\left(P_{P}=10 \%, P_{I}=40 \%, P_{Z}=50 \%\right)$ for bus\#7.

Table (2): Main results for bus\#7 (starting active power $=228.02 \mathrm{MW}$ ).

\begin{tabular}{||c||c||c||c|c|c|c||}
\hline $\begin{array}{c}\text { Constant } \\
\text { power } \\
\text { load[\%] }]\end{array}$ & $\begin{array}{c}\text { Constant } \\
\text { current } \\
\text { load[\%] }\end{array}$ & $\begin{array}{c}\text { Constant } \\
\text { impedance } \\
\text { load[\%] }\end{array}$ & $\begin{array}{c}\text { Active } \\
\text { power at } \\
\text { collapse } \\
\text { [pu] }\end{array}$ & $\begin{array}{c}\text { Maximum } \\
\text { power } \\
{[\mathrm{pu}]}\end{array}$ & $\begin{array}{c}\text { High } \\
\text { Voltage } \\
\text { solution at } \\
\text { collapse[pu] }\end{array}$ & $\begin{array}{c}\text { Low } \\
\text { Voltage } \\
\text { solution at } \\
\text { collapse[pu] }\end{array}$ \\
\hline \hline 100 & 0 & 0 & 17.5802 & 17.5802 & 0.6834 & 0.6544 \\
\hline 70 & 30 & 0 & 17.7076 & 17.7201 & 0.6507 & 0.5704 \\
\hline 70 & 0 & 30 & 17.7522 & 17.8195 & 0.6293 & 0.5548 \\
\hline 40 & 60 & 0 & 17.2393 & 17.8438 & 0.5570 & 0.4908 \\
\hline 40 & 30 & 30 & 16.9200 & 17.9395 & 0.5230 & 0.4835 \\
\hline 40 & 0 & 60 & 16.8212 & 18.0318 & 0.5091 & 0.4594 \\
\hline 10 & 70 & 20 & 13.3673 & 18.0252 & 0.3512 & 0.2940 \\
\hline 10 & 50 & 40 & 12.2868 & 18.0857 & 0.3118 & 0.3058 \\
\hline 10 & 40 & 50 & 12.4329 & 18.1151 & 0.3161 & 0.2858 \\
\hline 10 & 20 & 70 & 11.8638 & 18.1738 & 0.2961 & 0.2802 \\
\hline
\end{tabular}




\section{Light load bus (bus \#149)}

The active power at bus \#149 is 17.18MW. Similarly, Figure 9 shows the power and voltage behavior for dominant constant impedance and current loads $\left(\mathrm{P}_{\mathrm{P}}=10 \%, \mathrm{P}_{\mathrm{I}}=40\right.$ $\%, \mathrm{P}_{\mathrm{Z}}=50 \%$ ). The main results for some selected load models are shown in Table 3 .
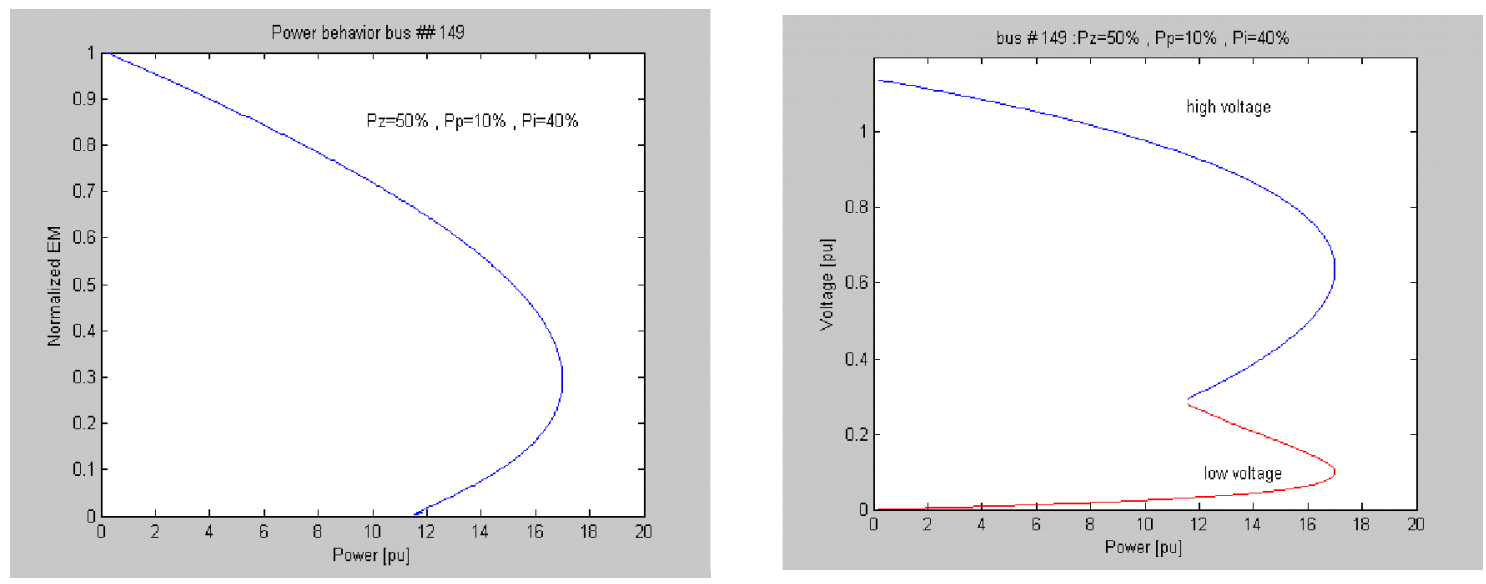

Figure (9): Power and voltage behavior $\left(P_{P}=10 \%, P_{I}=40 \%, P_{Z}=50 \%\right)$ for bus\#149.

Table (3): Main results for bus\#149 (starting active power $=17.18 \mathrm{MW}$ ).

\begin{tabular}{||c||c||c||c|c|c|c||}
\hline $\begin{array}{c}\text { Constant } \\
\text { power } \\
\text { load[\%] }\left[\begin{array}{c}\text { Constant } \\
\text { current } \\
\text { load[\%] }\end{array}\right.\end{array}$ & $\begin{array}{c}\text { constant } \\
\text { load [\%] }\end{array}$ & $\begin{array}{c}\text { Active } \\
\text { power at } \\
\text { collapse } \\
{[\mathrm{pu}]}\end{array}$ & $\begin{array}{c}\text { maximum } \\
\text { power } \\
{[\mathrm{pu}]}\end{array}$ & $\begin{array}{c}\text { High } \\
\text { Voltage } \\
\text { solution at } \\
\text { collapse[pu] }\end{array}$ & $\begin{array}{c}\text { Low Voltage } \\
\text { solution at } \\
\text { collapse[pu] }\end{array}$ \\
\hline \hline 100 & 0 & 0 & 16.8719 & 16.8719 & 0.6776 & 0.6199 \\
\hline 70 & 30 & 0 & 16.9148 & 16.9424 & 0.6230 & 0.5534 \\
\hline 70 & 0 & 30 & 16.8529 & 16.9590 & 0.5985 & 0.5445 \\
\hline 40 & 60 & 0 & 16.2257 & 16.9669 & 0.5209 & 0.4779 \\
\hline 40 & 30 & 30 & 16.3042 & 16.9788 & 0.5248 & 0.4402 \\
\hline 40 & 0 & 60 & 15.9684 & 16.9870 & 0.4956 & 0.4373 \\
\hline 10 & 70 & 20 & 12.4408 & 16.9936 & 0.3263 & 0.2795 \\
\hline 10 & 50 & 40 & 12.1582 & 16.9972 & 0.3154 & 0.2694 \\
\hline 10 & 40 & 50 & 11.8798 & 16.9986 & 0.3030 & 0.2855 \\
\hline 10 & 20 & 70 & 11.1461 & 17.0005 & 0.2799 & 0.2732 \\
\hline \hline
\end{tabular}


As a conclusion, higher constant impedance and constant current load percentages, and especially constant impedance, apparently decrease the system stability until reaching first a critical power level (maximum power). This maximum power occurs at a voltage level not much lower than the system nominal value. Any further increase of load fails to raise the system power beyond that critical power level (maximum power). On the contrary, the system total power starts to decrease due to the dependency of such loads on the voltage levels, which continues dropping until reaching the collapse point at a power level very much lower than the maximum power.

\section{Conclusions:}

The sparse network formulation of energy function technique retains the original structure of the system network and avoids network reduction. This permits the system loads to be modeled as they exist in practical life including constant power, constant current and constant impedance loads. Neglecting these models may lead to misleading results. A closed form expression of the energy function including load modeling effect has been has been obtained. The significant effect of on power system voltage stability has been investigated through an application to Ontario-Hydro (55-bus) real power system (Canada). The load modeling effect on both power and voltage behavior and consequently on the system voltage stability of three load buses that represent different load categories has been emphasized.

\section{References:}

[1] M. Abu-Elnaga, Major Blackouts and Failures of Power Systems Main Causes, Consequences, and Preventive Measures, Proceedings of the Seventh Middle East Power Systems Conference MEPCON'2000, Ain Shams University, Egypt, pp. 702-713, March 2000.

[2] E.A. Mohamed, Power System Steady State Voltage Stability Assessment, Proceedings of the Seventh Middle East Power Systems Conference MEPCON'2000, Ain Shams University, Egypt, March 2000.

[3] M.Z. El-Sadek, Preventive Measures for Voltage Collapses and Voltage Failures in the Egyptian Power System, Electric Power System Research, Vol. 44, No. 3, 1998.

[4] P-A Lof, G Anderson and D J Hill, Voltage Stability Indices for Stressed Power Systems, IEEE Transactions on Power Systems, Vol. 8, No. 1, February 1993.

[5] F. Gubina, A. Tribuson and P.A. Omahen, Algorithm for Protection Against Voltage Collapse, Proceedings of the $29^{\text {th }}$ Universities Power Engineering Conference. Part 1, pp. 553-556, Galway, Irel, 1994. 
[6] F. Gubina and B. Strmcnik, Voltage Collapse Proximity Index Determination Using Voltage Phasors, IEEE Transactions on Power Systems, Vol. 10, No. 2, pp. 788-794, May 1995.

[7] Chiang, H, R. Jean-Jumeau, Toward a practical performance index for predicting voltage collapse in electric power systems, IEEE Transactions on Power Systems, V 10, n 2, pp. 584-592, May 1995.

[8] A. Canizares and F.L. Alvarado, Point of Collapse and Continuation Methods for Large AC/DC Systems, IEEE Transactions on Power Systems, Vol. 8, No. 1, pp. 1-8, Feb. 1993.

[9] F. Alvarado, I. Dobson and Y. Hu, Computation of Closest Bifurcations in Power Systems, IEEE Transactions on Power Systems, Vol. 9, No. 2, pp. 918-928, May 1994.

[10] C. A. Canizares, On bifurcations, voltage collapse and load modeling, IEEE Transactions on Power Systems, V 10, n 1, pp. 512-522, Feb. 1995.

[11] L. Vargas and V. H. Quintana, Clustering Techniques for Voltage Collapse Detection, Electric Power Systems Research, Vol. 26, No. 1, pp. 53-59, Jan. 1993.

A. Teshome and E. Esiyok, Distance to Voltage Collapse Through Second-Order

[12] Eigenvalue Sensitivity Technique, International Journal of Electrical Power and Energy System, Vol. 17, No. 6, pp. 425-431, Dec. 1995.

S. Abdelkader Determination of Lower Voltage Power Flow Solutions for Voltage

[13] Stability Assessment, Sixth Middle East Power Systems Conference MEPCON'98, Mansoura, Egypt, Dec. 15-17, 1998.

Z. S. Elrazaz, I. Yassin, A. Hegazy and H. Moustafa, Voltage Stability Indicators

[14] Via Artificial Neural Networks, Sixth Middle East Power Systems Conference MEPCON'98, Mansoura, Egypt, Dec. 15-17, 1998.

A.A. El-Keib and X. Ma, Application of Artificial Neural Networks in Voltage

[15] Stability Assessment, IEEE Transactions on Power Systems, Vol. 10, No. 4, November 1995, pp. 1890-1896.

M. La Scala, M. Trovato and F. Torelli, A Neural Network-Based Method for

[16] Voltage Security Monitoring, IEEE Transactions on Power Systems, Vol. 10, No. 3, August 1996, pp. 1332-1341.

F.M. Elkady and A.Y. Abdelaziz, Voltage Stability Assessment of Electrical

[17] Power Systems Using Artificial Neural Networks, Journal of Engineering and Applied Science, Faculty of Engineering, Cairo University, Vol. 48, No. 4, August 2001, pp. 727-743.

M. M. El-Kady at. al., Dynamic Security Assessment Utilizing the Transient

[18] Energy Function Method, IEEE Transactions on Power Systems, pp. 284-291, Aug. 1986. 
[19] M.M. Abu-Elnaga, Sparse Formulation of Lyapunov Direct Method Applied to Transient Stability of Large-Scale Systems, Ph.D. Thesis, Mc Master University, Hamilton, Ontario, Canada, 1987.

[20] Thomas J. Overbye, Use of Energy Methods for On-Line Assessment of Power System Voltage Security, IEEE Transactions on Power Systems, Vol. 8, No. 2, pp. 452-458, May 1993.

[21] K. L. Praprost and K.A. Loparo, Energy Function Method for Determining Voltage Collapse During a Power System Transient, IEEE Transactions on Circuits and Systems I: Fundamental Theory and Applications, Vol. 41, No. 10, pp. 635-651, Oct. 1994.

[22] A. Y. Abdelaziz, M. M. Abu-Elnaga, M. A. Elsharkawy and K. M. Elbahrawy, Voltage Stability Assessment of Multi-machine Power Systems using Energy Function and Neural Networks Techniques, Electric Power Components and Systems Journal, Vol. 34, No. 12, December 2006, pp. 1313-1330.

[23] Abu-Elnaga M. M., The Effect Of Load Modeling On Power System Security, Scientific Bulletin, Ain Shams University, Faculty of Engineering, Vol. 39, No. 1, pp 707-716, Cairo, Egypt, March, 2004.

[24] Abu-Elnaga M. M., Ann-Based Technique For Power System Security with Load Modeling Effect, Scientific Bulletin, Ain Shams University, Faculty of Engineering, Vol. 40, No. 3, pp 653-663, Cairo, Egypt, September, 2005.

[25] Christopher L. DeMarco and Thomas J. Overbye, An Energy Based Security Measure for Assessing Vulnerability to Voltage Collapse, IEEE Transactions on Power Systems, Vol. 5, No. 2, May 1990, pp. 419-425.

[26] Fouad A.A.,Transient Stability Margin as a Tool for Dynamic Security Assessment, EPRI report El-1755 project 1355-3, march 1991. 


\section{Nomenclatures:}

$V, \alpha \quad$ Voltage magnitude and angle

$\omega \quad$ Speed deviation

$0, \alpha^{o}, V^{o} \quad$ express the HVS

$\omega, \alpha, V \quad$ express the LVS

$f(\alpha, V) \quad$ Constraint functions that represents the active power balance equation

$g(\alpha, V) \quad$ Constraint functions that represents the reactive power balance equation

$\mathrm{Y}_{\mathrm{ij}} \angle \beta_{\mathrm{ij}}$ Admittance of transmission line connecting bus " $i$ " and bus " $j$ " in polar form $(i \neq j)$ and $Y_{i i}$ represents the self admittance of bus $i$,

$\mathrm{G}_{\mathrm{ij}}+\mathrm{jB}_{\mathrm{ij}}$ Admittance of transmission line connecting bus " $i$ " and bus " $j$ " in rectangular form $(\mathrm{i} \neq \mathrm{j})$

$\mathrm{V}_{i} \angle \alpha \quad$ Voltage of bus $i$ in polar form

$\mathrm{P}_{\mathrm{i}}, \mathrm{Q}_{\mathrm{i}} \quad$ Active and reactive load powers active and reactive load powers 